\title{
Curcumin suppresses migration and invasion of human endometrial carcinoma cells
}

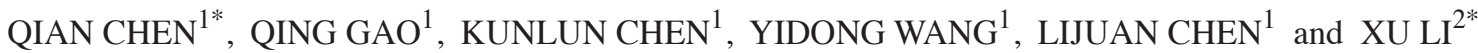 \\ ${ }^{1}$ Department of Obstetrics and Gynecology, The Second Affiliated Hospital, Medical School of Xi'an Jiaotong University, \\ Xi'an, Shaanxi 710004; ${ }^{2}$ Center for Translational Medicine, The First Affiliated Hospital, \\ Medical School of Xi'an Jiaotong University, Xi'an, Shaanxi 710061, P.R. China
}

Received July 20, 2014; Accepted May 12, 2015

DOI: $10.3892 / \mathrm{ol} .2015 .3478$

\begin{abstract}
Curcumin, a widely used Chinese herbal medicine, has historically been used in anti-cancer therapies. However, the anti-metastatic effect and molecular mechanism of curcumin in endometrial carcinoma (EC) are still poorly understood. The purpose of this study was to detect the anti-metastatic effects of curcumin and the associated mechanism(s) in EC. Based on assays carried out in EC cell lines, it was observed that curcumin inhibited EC cell migration and invasion in vitro. Furthermore, following treatment with curcumin for $24 \mathrm{~h}$, there was a decrease in the expression levels of matrix metalloproteinase (MMP)-2 and -9 as well as proteinase activity in EC cells. Moreover, curcumin treatment significantly decreased the levels of the phosphorylated form of extracellular signalregulated kinase (ERK) 1/2. MEK1 overexpression partially blocked the anti-metastatic effects of curcumin. Combined treatment with ERK inhibitor U0126 and curcumin resulted in a synergistic reduction in MMP-2/-9 expression; the invasive capabilities of HEC-1B cells were also inhibited. In conclusion, curcumin inhibits tumor cell migration and invasion by reducing the expression and activity of MMP-2/9 via the suppression of the ERK signaling pathway, suggesting that curcumin is a potential therapeutic agent for EC.
\end{abstract}

Correspondence to: Professor $\mathrm{Xu} \mathrm{Li}$, Center for Translational Medicine, The First Affiliated Hospital, Medical School of Xi'an Jiaotong University, 277 Yanta West Street, Xi'an, Shaanxi 710061, P.R. China

E-mail: lixu201415@163.com

Dr Qian Chen, Department of Obstetrics and Gynecology, The Second Affiliated Hospital, Medical School of Xi'an Jiaotong University, 154 West Five Road, Xi'an, Shaanxi 710004, P.R. China E-mail: chenqian@mail.xjtu.edu.cn

*Contributed equally

Key words: curcumin, endometrial carcinoma, invasion, extracellular signal-regulated kinase

\section{Introduction}

With its increasing incidence, endometrial carcinoma (EC) is now the most common gynecological type of cancer in developed countries (1). The incidence of EC has also increased in China over the past 20 years, with an increase of over $100 \%$ in the overall mortality rate from EC during this time (2). Type I (endometrioid) EC is usually considered to be low risk and is normally treatable. Conversely, type II EC has a non-endometrioid histology with a high incidence of deep myometrial invasion and lymph node metastasis, which leads to a poor prognosis and significant mortality (3).

Identification of the mechanisms underlying the invasion of EC is likely to assist in the development of novel therapeutic approaches. The process of metastasis of EC cells is complicated. During the process, matrix metalloproteinase (MMP)-2 and -9 play significant roles by degrading the extracellular matrix (ECM) (4). MMP-2 and -9 also play key roles in the metastasis of EC and are closely correlated with the progression of EC $(5,6)$.

Curcumin, an active component of the spice turmeric (Curcuma longa), has chemopreventive and therapeutic properties against numerous tumors in vitro and in vivo (7). However, to date there have been no studies into the anti-metastatic effect of curcumin on EC.

In the present study, we aim to elucidate the anti-metastatic effect of curcumin on EC and its associated mechanisms.

\section{Materials and methods}

Cell lines and cell culture. HEC-1B and Ishikawa cell lines were obtained from the cell bank of the Chinese Academy of Science (Shanghai, China). Cells were all cultured in Dulbecco's modified Eagle's medium (DMEM; Life Technologies, Darmstadt, Germany) or DMEM-F12 with $10 \%$ fetal bovine serum (FBS; Life Technologies, Darmstadt, Germany) and incubated in a humidified atmosphere of $5 \% \mathrm{CO}_{2}$ at $37^{\circ} \mathrm{C}$.

Assessment of cell viability. Cell viability was determined by a colorimetric 3-(4,5-dimethylthiazol-2-yl) 2,5-diphenyltetrazolium bromide (MTT) assay in accordance with previously described protocols. Briefly, cells were plated in 96 -well culture plates $\left(2 \times 10^{4}\right.$ cells per well) then treated for 
24,48 and $72 \mathrm{~h}$ with various concentrations of curcumin. The cells were then washed twice with phosphate-buffered saline (PBS) and incubated with $5 \mathrm{mg} / \mathrm{ml} \mathrm{MTT} \mathrm{(Sigma-Aldrich,}$ St. Louis, MO, USA) for $4 \mathrm{~h}$. Then, cells were washed with PBS and solubilized with dimethyl sulfoxide.

Migration and invasion assay. Cells were seeded into a six-well plate and cultured to $70 \%$ confluence in medium containing $10 \%$ FBS. Cell monolayers were scratched with a plastic tip $(1 \mathrm{~mm})$ and then incubated in serum-containing medium (1\% serum) with $0,10,20$ and $30 \mu \mathrm{M}$ curcumin for $24 \mathrm{~h}$. The migration distance of the cells was measured at three sites using Photoshop software (Adobe Systems, Inc., San Jose, CA, USA). The migration rate was expressed as a percentage of the control.

The invasion potential of the cancer cells was assessed in vitro using Transwell chambers (Corning Incorporated, Corning, New York, NY, USA). First, the upper chambers were coated with Matrigel (BD Biosciences, San Jose, CA, USA), then $1 \times 10^{6}$ cells in serum-free medium were added to the upper chambers, and FBS $(10 \%)$ was added to the bottom chambers. Cells on the bottom side of the filter were fixed, stained and counted. For transfection experiments, cells were seeded $24 \mathrm{~h}$ after transfection. The rate of invasive cells was expressed as a percentage of the control.

Construction of expression plasmids and transfection. The expression plasmids were provided by Dr Chen and the transfection was performed as described previously (4). Briefly, the full-length pcDNA3.1 (Invitrogen Life Technologies, Carlsbad, CA, USA) MEK1 vector was prepared by cloning the full-length polymerase chain reaction product of MEK1 with KOD ${ }^{\circledR}$ DNA polymerase (Toyobo, Osaka, Japan). DNA sequencing was used to confirm the plasmid sequences. For transient transfection experiments, cells were plated $24 \mathrm{~h}$ prior to transfection in a six-well plate at a density of $2 \times 10^{5}$ cells per well. Lipofectamine 2000 (Invitrogen) was used with $4.0 \mu \mathrm{g}$ pcDNA3.1(+)-MEK1 vector or $4.0 \mu \mathrm{g}$ pcDNA3.1(+) empty vector as a negative control in accordance with the manufacturer's instructions.

Western blotting analysis. Following treatment with various concentrations of curcumin or U0126 (Sigma), 2x10 6 cells were suspended in $200 \mu \mathrm{l}$ lysis buffer $(1 \mathrm{mmol} / 1$ EDTA, $40 \mathrm{mmol} / \mathrm{l}$ Tris- $\mathrm{HCl}, 150 \mathrm{mmol} / \mathrm{l} \mathrm{KCl}, 1 \%$ Triton $\mathrm{X}-100$, $100 \mathrm{mmol} / 1 \mathrm{NaVO}_{3}$ and $1 \mathrm{mmol} / 1$ phenylmethylsulfonyl fluoride; $\mathrm{pH} 7.5)$. The proteins $(80 \mu \mathrm{g})$ were separated by 10 or $12 \%$ sodium dodecyl sulphate-polyacrylamide gel electrophoresis (SDS-PAGE) and then transferred onto polyvinylidene fluoride membranes. After being blocked in defatted milk (5\% in Tris-buffered saline with Tween-20 buffer) at $37^{\circ} \mathrm{C}$, the membranes were incubated with various antibodies against MMP-2, MMP-9, extracellular signal-regulated kinase (ERK) $1 / 2$, p-ERK1/2 or $\beta$-actin (all from Cell Signaling Technology, Inc., Danvers, MA, USA) overnight at $4^{\circ} \mathrm{C}$. The membranes were then incubated with appropriate secondary antibodies for $1 \mathrm{~h}$ at room temperature. The bands were detected and expressed as arbitrary units. Densitometric analysis was performed using ImageQuant TL software (GE Healthcare, Chalfont, Bucks, UK).
Zymography. The assay was performed as previously described (8). Following treatment with various concentrations of curcumin for $24 \mathrm{~h}$, samples of conditioned cell media were collected and separated by $0.1 \%$ gelatin $8 \%$ SDS-PAGE electrophoresis. Then, the gels were washed twice in $2.5 \%$ Triton X-100 for $45 \mathrm{~min}$ at room temperature and then incubated in reaction buffer $\left(40 \mathrm{mM}\right.$ Tris- $\mathrm{HCl}, 10 \mathrm{mM} \mathrm{CaCl}_{2}$ and $0.01 \% \mathrm{NaN}_{3} ; \mathrm{pH} 8.0$ ) at $37^{\circ} \mathrm{C}$ for $14 \mathrm{~h}$. The gels were stained with Coomassie brilliant blue R-250 gel stain. The intensities of bands on the gels were calculated using an image analysis system (Bio-Rad Laboratories, Richmond, CA, USA). The final volumes of the samples were adjusted by counting the viable cell number.

Statistical analysis. Experiments were repeated three times, and dates were analyzed using Student's t-test. All statistical tests and corresponding $\mathrm{P}$-values were two-sided. $\mathrm{P}<0.05$ was considered to indicate a statistically significant difference. Correlation analysis was performed using the Z-test.

\section{Results}

Curcumin inhibits proliferation of HEC-1B cells. The anti-proliferation effects of curcumin at various concentrations (0 to $100 \mu \mathrm{M})$ on HEC-1B cells are shown in Fig. 1. At $40 \mu \mathrm{M}$, curcumin significantly inhibited the proliferation of HEC-1B cells. At concentrations below $40 \mu \mathrm{M}$, the anti-proliferative effect was not evident. Thus, a concentration range of curcumin lower than this was selected for all subsequent experiments.

Curcumin inhibits motility and invasion of HEC-1B cells. Since cell motility is a measure of the metastatic potential of cancer cells, the motility of HEC-1B cells was examined. As shown in Fig. 2A, a continuous rapid movement was observed in control cells. The movement of HEC-1B cells was significantly reduced following treatment with curcumin in a concentration-dependent manner; the inhibition rates were $\sim 65.33,69.23$ and $90.07 \%$ at $24 \mathrm{~h}$ with 10,20 and $30 \mu \mathrm{M}$ curcumin, respectively (Fig. 2B). Fig. $2 \mathrm{C}$ reveals the effect of curcumin on the invasiveness of HEC-1B cells that were treated with $0,10,20$ and $30 \mu \mathrm{M}$ of curcumin for $24 \mathrm{~h}$. Curcumin reduced the invasion of HEC-1B cells substantially in a concentration-dependent manner. A similar anti-metastatic effect of curcumin was observed in Ishikawa cells (results not shown). Quantification analysis indicated that the invasiveness of HEC-1B cells was reduced by $18.58,51.89$ and $73.58 \%$ when cells were treated with 10,20 and $30 \mu \mathrm{M}$ of curcumin (Fig. 2D), respectively. Curcumin also inhibits the invasion of Ishikawa cells (results not shown).

Curcumin suppressed expression and activity of MMP-2 and MMP-9. MMPs are crucial to cell invasion, so the expression of MMP-2/-9 in EC cells that were exposed to various concentrations of curcumin was measured. HEC-1B cells were treated with $0,10,20$ and $30 \mu \mathrm{M}$ curcumin for $24 \mathrm{~h}$, and then subjected to western blotting. Fig. 3A and $B$ reveal that curcumin significantly reduced the protein levels of MMP-2/-9 in a concentration-dependent manner compared with the control group in HEC-1B cells. Fig. 3C 


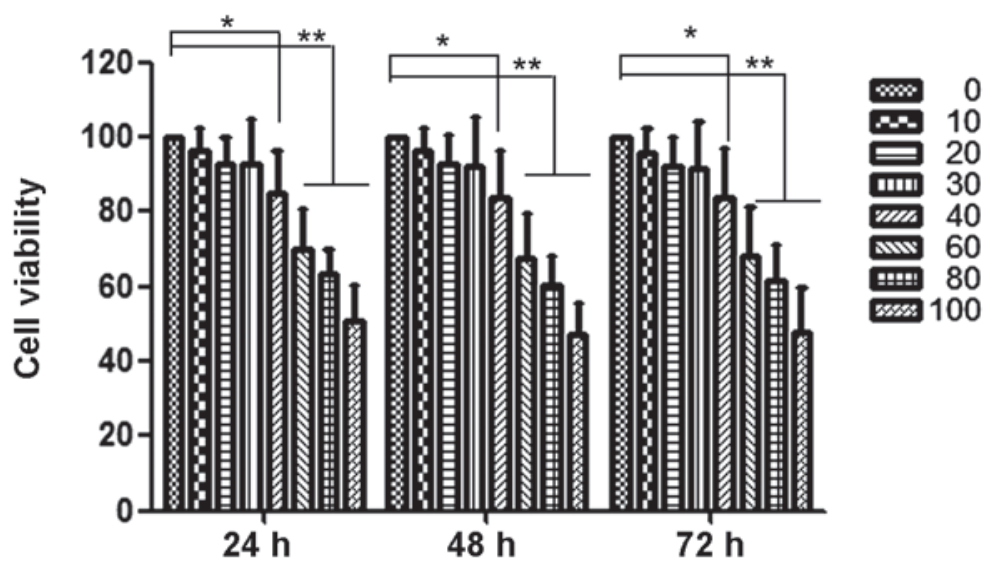

Figure 1. Curcumin reduces the cellular viability of HEC-1B. HEC-1B cells were treated with 0 to $100 \mu \mathrm{M}$ curcumin for 24,48 and $72 \mathrm{~h}$, and their viability was then measured using a 3-(4,5-dimethylthiazol-2-yl) 2,5-diphenyltetrazolium bromide assay. Data are reported as the means \pm standard deviation of three independent experiments, each performed in triplicate. ${ }^{*} \mathrm{P}<0.05$ and ${ }^{* *} \mathrm{P}<0.01$ compared with control group.
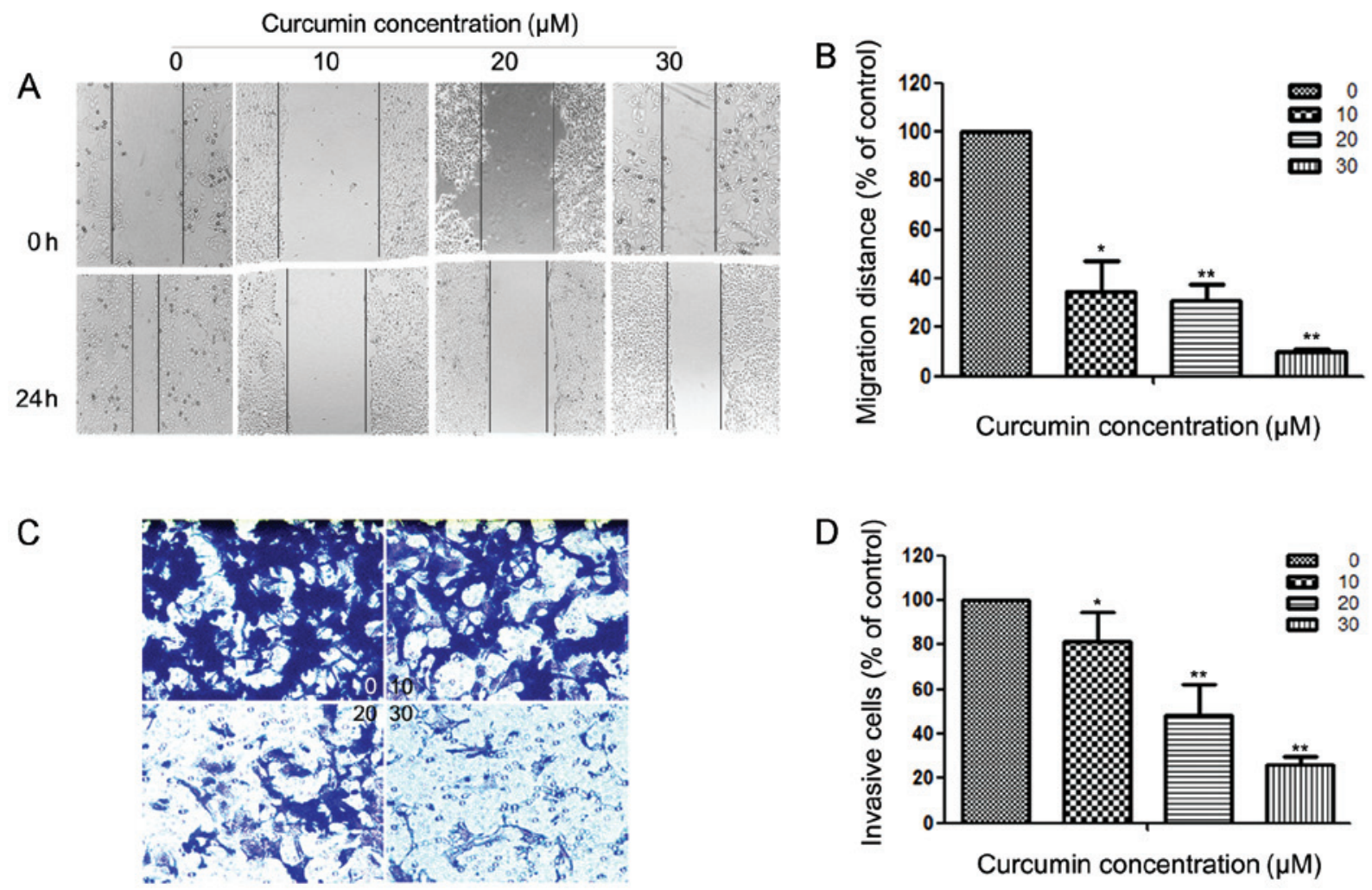

Figure 2. Effects of curcumin on the motility and invasiveness of HEC-1B cells in vitro. (A) HEC-1B cells were scratched and then incubated in media containing $2 \%$ serum with varying concentrations of curcumin $(0,10,20$ and $30 \mu \mathrm{M})$ for $24 \mathrm{~h}$. Images were captured at 0 and $24 \mathrm{~h}$ after addition of curcumin. (B) The migration rate is expressed as a percentage of the control $(0 \mu \mathrm{M})$. (C) HEC-1B cells were pretreated with $0,10,20$ and $30 \mu \mathrm{M}$ curcumin for $24 \mathrm{~h}$ and then seeded in the upper chambers of a Transwell. Fetal bovine serum (10\%) was added to the bottom chambers for $24 \mathrm{~h}$ to induce cell invasion. After $24 \mathrm{~h}$, cells on the bottom side of the filter were fixed, stained and counted. Magnification, x100. (D) The invasion rate is expressed as a percentage of the control $(0 \mu \mathrm{M})$. Values represent the means \pm standard deviation of three independent experiments performed in triplicate. ${ }^{*} \mathrm{P}<0.05$ and ${ }^{* *} \mathrm{P}<0.01$ compared with the control group.

and $\mathrm{D}$ reveal similar results for the activity of MMP-2/-9 in HEC-1B cells.

ERK pathway is involved in the anti-metastatic mechanism of curcumin. To further investigate the mechanisms underlying the anti-metastatic effect of curcumin, western blotting was used to detect the expression of ERK1/2 and p-ERK1/2 in
HEC-1B cells. Western blotting revealed that curcumin reduced the phosphorylation of ERK1/2 in a concentration-dependent manner (Fig. 4A and B).

To further analyze the exact effect of curcumin on the ERK pathway, we transfected HEC-1B cells with a plasmid (pcDNA3.1(+)-MEK1) expressing human MEK1 (Fig. 5D). Following transfection, activity of the ERK signaling pathway 
A

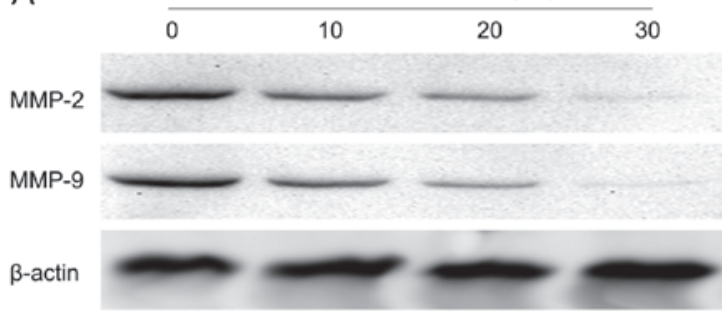

C

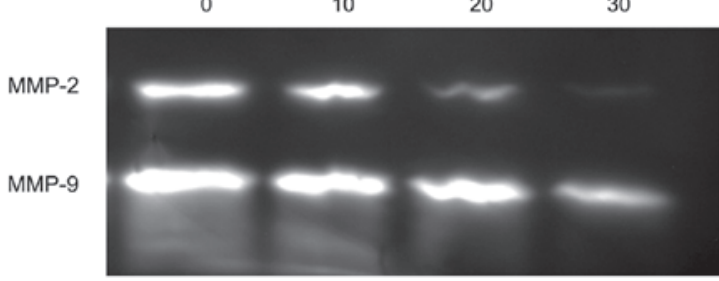

B

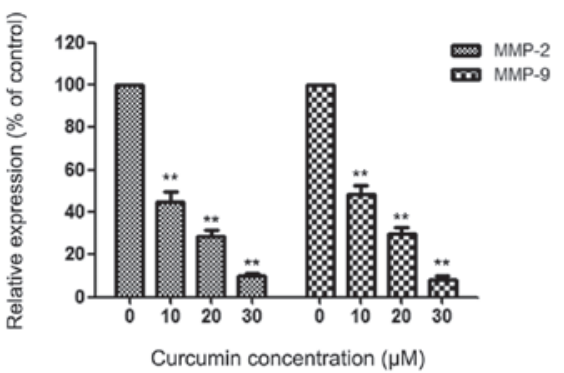

D

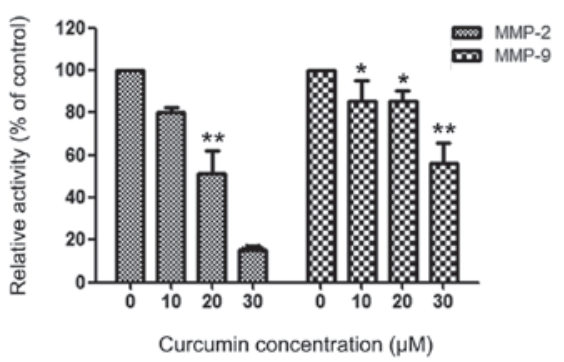

Figure 3. Curcumin suppresses the expression of matrix metalloproteinase (MMP)-2 and MMP-9 in HEC-1B cells. (A) HEC-1B cells were treated with curcumin $(0,10,20$ and $30 \mu \mathrm{M})$ for $24 \mathrm{~h}$ and then subjected to western blotting to analyze the protein levels of MMP-2/-9. (B) Quantification of the protein levels of MMP-2/-9 in HEC-1B cells. (C) HEC-1B cells were treated with curcumin $(0,10,20$ and $30 \mu \mathrm{M})$ for $24 \mathrm{~h}$ and then subjected to zymography to analyze the activity of MMP-2/-9. (D) Quantification of the activity of MMP-2/-9 in HEC-1B cells. Values represent the means \pm standard deviation of three independent experiments performed in triplicate. ${ }^{*} \mathrm{P}<0.05$ and ${ }^{* *} \mathrm{P}<0.01$ compared with control group.

A

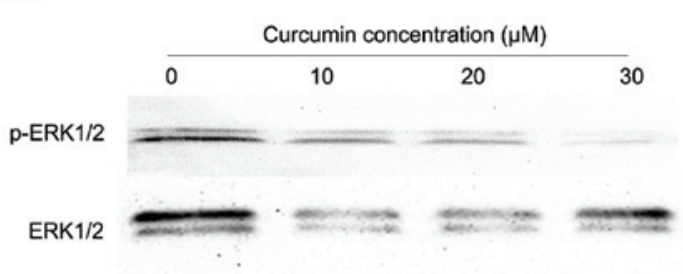

C
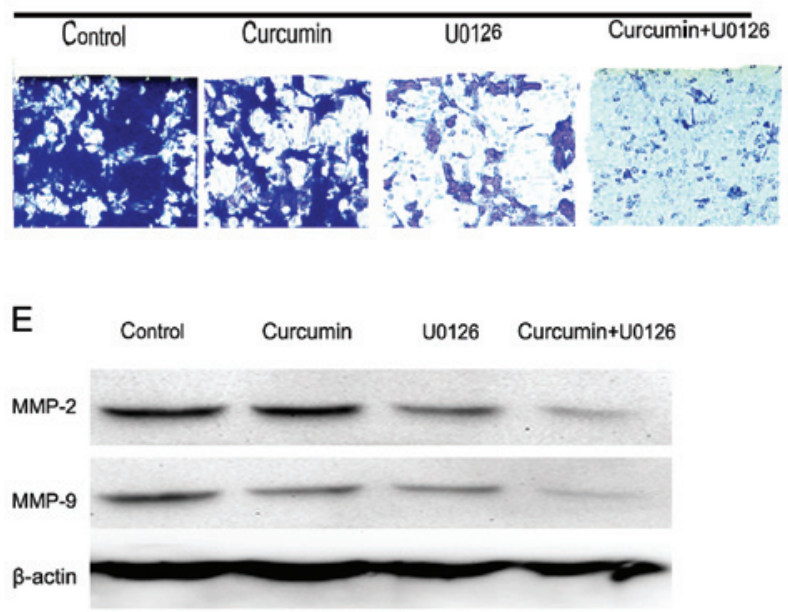
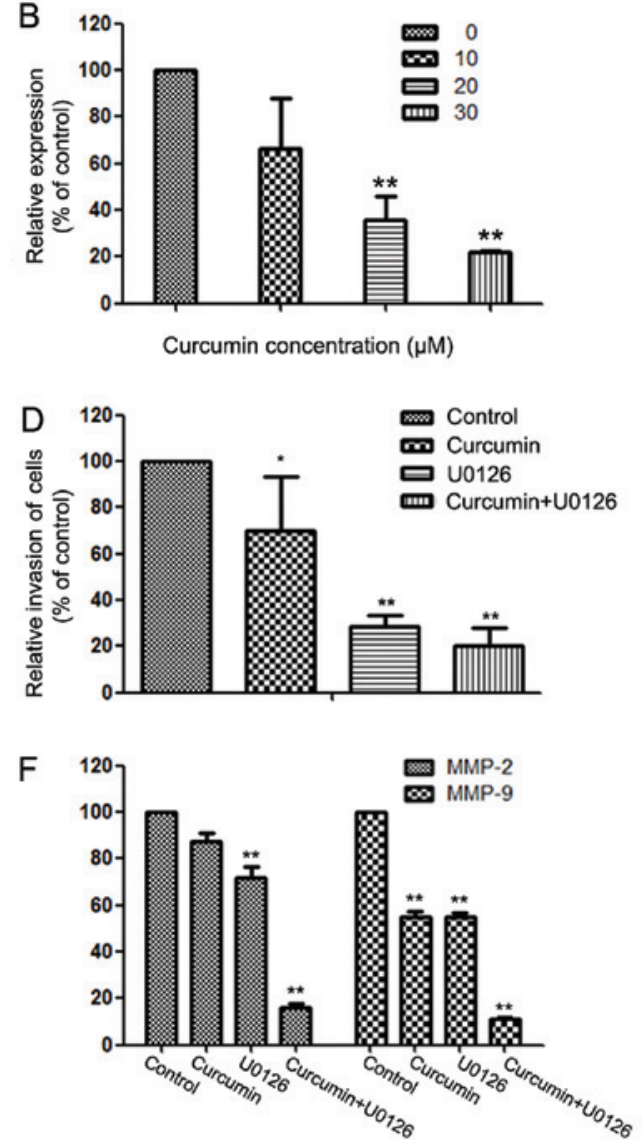

Figure 4. Effect of curcumin on the extracellular signal-regulated kinase (ERK) pathway, and effects of the ERK inhibitor (U0126) and curcumin on cell invasion and matrix metalloproteinase (MMP)-2/-9 expression in HEC-1B cells. (A) Protein levels of ERK1/2 and p-ERK1/2. (B) Quantification of the protein levels of ERK1/2 and p-ERK1/2. (C) Cells were pretreated with U0126 $(10 \mu \mathrm{M})$ for $30 \mathrm{~min}$ and then incubated in the presence or absence of curcumin $(10 \mu \mathrm{M})$ for $24 \mathrm{~h}$. Cellular invasiveness was measured using the Transwell chamber invasion assay. Magnification, x100. (D) The invasion rate is expressed as a percentage of the control. (E and F) HEC-1B cells were treated with U0126 $(10 \mu \mathrm{M})$ for $30 \mathrm{~min}$, then incubated in the presence or absence of curcumin $(10 \mu \mathrm{M})$ for $24 \mathrm{~h}$ and then subjected to western blotting to analyze the protein levels of MMP-2/-9. Values represent the means \pm standard deviation of three independent experiments performed in triplicate. ${ }^{*} \mathrm{P}<0.05$ and ${ }^{* *} \mathrm{P}<0.01$ compared with control group. 
A

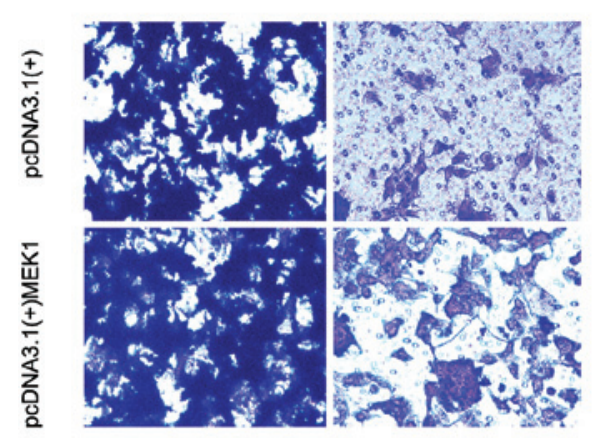

C

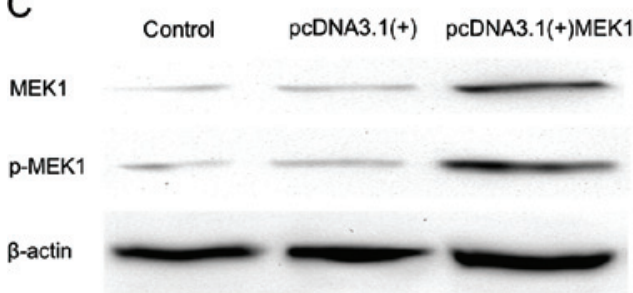

B

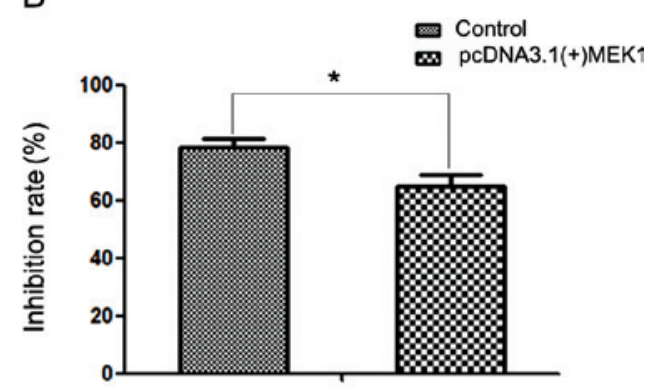

$\mathrm{D}$

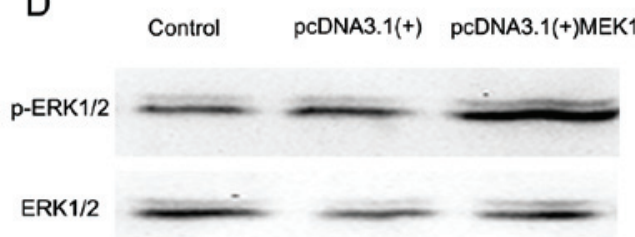

Figure 5. Ectopic expression of MEK1 reversed the inhibitory effect of curcumin on cell invasion. (A) Transwell assays were performed to evaluate the anti-metastatic effects of curcumin $(10 \mu \mathrm{M})$ on two groups of cells transfected with the indicated plasmids (empty vector pcDNA3.1(+) or pcDNA3.1(+)-MEK1). Magnification, x100. (B) Inhibition rates of curcumin on the two groups of cells. The inhibition rate is expressed as the inhibition cells as a percentage of the control (the control group of cells transfected with empty vector pcDNA3.1(+) or with pcDNA3.1(+)-MEK1, without treatment of curcumin). Values represent the means \pm standard deviation of three independent experiments performed in triplicate. ${ }^{*} \mathrm{P}<0.05$ and ${ }^{* *} \mathrm{P}<0.01$ compared with the control group. (C) Western blotting was performed to detect the expression of MEK1 and p-MEK1 in three groups of HEC-1B cells: no transfection (control), cells transfected with empty vector pcDNA3.1(+) (negative control group), and cells transfected with pcDNA3.1(+)-MEK1 (positive group). (D) Western blotting was performed to detect extracellular signal-regulated kinase (ERK) activity in the three groups of HEC-1B cells.

was increased (Fig. 5C). It was also observed that MEK1 reversed the inhibitory effect of curcumin on cell invasion (Fig. 5A and B). The reduction in the inhibition rate in the pcDNA3.1(+) group and the pcDNA3.1(+)-MEK1 group was $~ 78.4$ and $64.92 \%$ following $24 \mathrm{~h}$ of treatment with $30 \mu \mathrm{M}$ curcumin, respectively.

To further investigate whether the inhibitory effect of curcumin on cell invasion and MMP-2/-9 expression was correlated with inhibition of the ERK pathway, HEC-1B cells were pretreated with an ERK inhibitor (U0126; $10 \mu \mathrm{M}$ ) for $30 \mathrm{~min}$ and then incubated in the presence or absence of curcumin $(10 \mu \mathrm{M})$ for $24 \mathrm{~h}$. The cells with the indicated pretreatment were then subjected to in vitro invasion assay. The results reveal that treatment with U0126 and curcumin significantly reduced cell invasion (Fig. 4C and D) as well as MMP-2 and -9 protein expression (Fig. 4E and F).

\section{Discussion}

In this study, curcumin was demonstrated to inhibit the migration and invasion of EC cells by inhibiting the expression and activity of MMP-2 and -9 through regulation of the ERK signaling pathway. Curcumin has been demonstrated to possess an antitumor effect in numerous types of cancer (9-11). Treatment with either letrozole or curcumin inhibited the xenografted endometrial tumor growth by inducing apoptosis in tumor cells, and the combination of letrozole and curcumin further strengthened the inhibitory effect on tumor growth (12). Another study also identified that curcumin induced the apoptosis of EC cells (13). However, until now there have been no studies on the anti-metastatic of effect curcumin on EC cells.
In the study, we observed that curcumin inhibited the migration of EC cells at non-cytotoxic concentrations. Curcumin was also observed to inhibit the invasion of EC cells at non-cytotoxic concentrations. MMP-2 and -9 play a significant role in the metastasis of tumor cells (14-16). By degrading the ECM, MMP-2 and -9 make the metastasis of tumor cells possible. A previous study established that curcumin inhibited the expression and activity of MMP-2/-9 in tumor cells (17-20). In the present study, we observed that curcumin inhibited the expression and activity of MMP-2/-9 in EC cells. The results reveal that the anti-metastatic effect of curcumin is correlated with MMP-2/-9.

The ERK signaling pathway is overactivated in a number of tumors (21). The ERK signaling pathway plays a crucial role in regulating the proliferation, survival and invasion of EC $(22,23)$. The synthesis of MMP-2 and -9 is regulated by a number of signaling pathways, including the ERK signaling pathway (24-26). Curcumin has been demonstrated to be capable of inhibiting the activity of the ERK signaling pathway $(27,28)$. Other researchers have observed that curcumin inhibited the expression and activity of MMPs by regulating the ERK signaling pathway $(29,30)$. In our study, curcumin was demonstrated to inhibit the activity of the ERK signaling pathway. Combined treatment with U0126 generated a synergistic effect on the migration and invasion of EC cells, further reducing the expression of MMP-2 and -9 in EC cells. Ectopic expression of MEK1 reversed the inhibitory effect of curcumin on cell invasion.

In conclusion, curcumin inhibits the expression and activity of MMP-2 and -9 by inhibiting the ERK signaling pathway. These findings reveal a new potential therapeutic application of curcumin in anti-metastatic therapy for EC. 


\section{Acknowledgements}

This study was supported by the National Natural Science Foundation of China (no. 81070536) and the Natural Science Foundation of Shaanxi Province (no. 2014JM4143).

\section{References}

1. Kitchener HC and Trimble EL: Endometrial cancer state of the science meeting. Int J Gynecol Cancer 19: 134-140, 2009.

2. Sorosky JI: Endometrial cancer. Obstet Gynecol 111: 436-447, 2008.

3. Barrena Medel NI, Bansal S, Miller DS, Wright JD and Herzog TJ: Pharmacotherapy of endometrial cancer. Expert Opin Pharmacother 10: 1939-1951, 2009.

4. Chen K, Zhang S, Ji Y, et al: Baicalein inhibits the invasion and metastatic capabilities of hepatocellular carcinoma cells via down-regulation of the ERK pathway. PLoS One 8: e72927, 2013

5. Weigel MT, Krämer J, Schem C, et al: Differential expression of MMP-2, MMP-9 and PCNA in endometriosis and endometrial carcinoma. Eur J Obstet Gynecol Reprod Biol 160: 74-78, 2012.

6. Karahan N, Güney M, Baspinar S, Oral B, Kapucuoglu N and Mungan T: Expression of gelatinase (MMP-2 and MMP-9) and cyclooxygenase-2 (COX-2) in endometrial carcinoma. Eur $\mathbf{J}$ Gynaecol Oncol 28: 184-188, 2007.

7. Naksuriya O, Okonogi S, Schiffelers RM and Hennink WE: Curcumin nanoformulations: a review of pharmaceutical properties and preclinical studies and clinical data related to cancer treatment. Biomaterials 35: 3365-3383, 2014.

8. Likhter MS, Shelygin IuA and Achkasov SI: Multidisciplinary approach to the treatment of colorectal cancer, complicated by urinary tract invasion. Khirurgiia (Mosk) 12: 34-39, 2012 (In Russian).

9. Chen J, Wang FL and Chen WD: Modulation of apoptosis-related cell signalling pathways by curcumin as a strategy to inhibit tumor progression. Mol Biol Rep 41: 4583-4594, 2014.

10. Wong TF, Takeda $\mathrm{T}$, Li B, et al: Curcumin targets the AKT-mTOR pathway for uterine leiomyosarcoma tumor growth suppression. Int J Clin Oncol 19: 354-363, 2014.

11. Ranjan AP, Mukerjee A, Helson L, Gupta R and Vishwanatha JK: Efficacy of liposomal curcumin in a human pancreatic tumor xenograft model: inhibition of tumor growth and angiogenesis. Anticancer Res 33: 3603-3609, 2013.

12. Liang YJ, Hao Q, Wu YZ, Wang QL, Wang JD and Hu YL: Aromatase inhibitor letrozole in synergy with curcumin in the inhibition of xenografted endometrial carcinoma growth. Int J Gynecol Cancer 19: 1248-1252, 2009.

13. Yu Z and Shah DM: Curcumin down-regulates Ets-1 and Bcl-2 expression in human endometrial carcinoma HEC-1-A cells. Gynecol Oncol 106: 541-548, 2007.

14. Sun W, Liu DB, Li WW, et al: Interleukin-6 promotes the migration and invasion of nasopharyngeal carcinoma cell lines and upregulates the expression of MMP-2 and MMP-9. Int J Oncol 44: 1551-1560, 2014

15. Park SL, Lee EJ, Kim WJ and Moon SK: p27KIP1 is involved in ERK1/2-mediated MMP-9 expression via the activation of $\mathrm{NF}-\kappa \mathrm{B}$ binding in the IL-7-induced migration and invasion of 5637 cells. Int J Oncol 44: 1349-1356, 2014.

16. Lee KR, Lee JS, Kim YR, Song IG and Hong EK: Polysaccharide from Inonotus obliquus inhibits migration and invasion in B16-F10 cells by suppressing MMP-2 and MMP-9 via downregulation of NF- $\mathrm{B}$ B signaling pathway. Oncol Rep 31: 2447-2453, 2014.
17. Lin HJ, Su CC, Lu HF, et al: Curcumin blocks migration and invasion of mouse-rat hybrid retina ganglion cells (N18) through the inhibition of MMP-2, -9, FAK, Rho A and Rock-1 gene expression. Oncol Rep 23: 665-670, 2010.

18. Qi Q, Dai M, Fan H, Zhang B and Yuan X: Inhibitory effect of curcumin on MMP-2 and MMP-9 expression induced by polyethylene wear particles and its mechanism. Zhongguo Xiu Fu Chong Jian Wai Ke Za Zhi 23: 677-682, 2009 (In Chinese).

19. Mitra A, Chakrabarti J, Banerji A, Chatterjee A and Das BR: Curcumin, a potential inhibitor of MMP-2 in human laryngeal squamous carcinoma cells HEp2. J Environ Pathol Toxicol Oncol 25: 679-690, 2006

20. Banerji A, Chakrabarti J, Mitra A and Chatterjee A: Effect of curcumin on gelatinase A (MMP-2) activity in B16F10 melanoma cells. Cancer Lett 211: 235-242, 2004.

21. Hoshino R, Chatani Y, Yamori T, et al: Constitutive activation of the $41-/ 43-\mathrm{kDa}$ mitogen-activated protein kinase signaling pathway in human tumors. Oncogene 18: 813-822, 1999.

22. Wang Y, Zhu Y, Zhang L, et al: Insulin promotes proliferation, survival and invasion in endometrial carcinoma by activating the MEK/ERK pathway. Cancer Lett 322: 223-231, 2012.

23. Tong JS, Zhang QH, Wang ZB, et al: ER- $\alpha 36$, a novel variant of ER- $\alpha$, mediates estrogen-stimulated proliferation of endometrial carcinoma cells via the PKCס/ERK pathway. PLoS One 5: e15408, 2010.

24. Zhang H, Shen B, Swinarska JT, Li W, Xiao K and He P: 9-Hydroxypheophorbide $\alpha$-mediated photodynamic therapy induces matrix metalloproteinase-2 (MMP-2) and MMP-9 down-regulation in Hep-2 cells via ROS-mediated suppression of the ERK pathway. Photodiagnosis Photodyn Ther 11: 55-62, 2014.

25. Shi MD, Shih YW, Lee YS, Cheng YF and Tsai LY: Suppression of 12-O-tetradecanoylphorbol-13-acetate-induced MCF-7 breast adenocarcinoma cells invasion/migration by $\alpha$-tomatine through

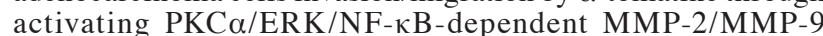
expressions. Cell Biochem Biophys 66: 161-174, 2013.

26. Dong QZ, Wang Y, Tang ZP, et al: Derlin-1 is overexpressed in non-small cell lung cancer and promotes cancer cell invasion via EGFR-ERK-mediated up-regulation of MMP-2 and MMP-9. Am J Pathol 182: 954-964, 2013.

27. Guo Y, Shan Q, Gong Y, et al: Curcumin induces apoptosis via simultaneously targeting AKT/mTOR and RAF/MEK/ERK survival signaling pathways in human leukemia THP-1 cells. Pharmazie 69: 229-233, 2014.

28. Xie YQ, Wu XB and Tang SQ: Curcumin treatment alters ERK-1/2 signaling in vitro and inhibits nasopharyngeal carcinoma proliferation in mouse xenografts. Int J Clin Exp Med 7: 108-114, 2014

29. Mo N, Li ZQ, Li J and Cao YD: Curcumin inhibits TGF- $\beta 1$-induced MMP-9 and invasion through ERK and Smad signaling in breast cancer MDA- MB-231 cells. Asian Pac J Cancer Prev 13: 5709-5714, 2012.

30. Shin HK, Kim J, Lee EJ and Kim SH: Inhibitory effect of curcumin on motility of human oral squamous carcinoma YD-10B cells via suppression of ERK and NF-kappaB activations. Phytother Res 24: 577-582, 2010. 